Supplement of Solid Earth, 10, 1905-1920, 2019

https://doi.org/10.5194/se-10-1905-2019-supplement

(C) Author(s) 2019. This work is distributed under

the Creative Commons Attribution 4.0 License.

(c) (i)

Supplement of

\title{
Extracting small deformation beyond individual station precision from dense Global Navigation Satellite System (GNSS) networks in France and western Europe
}

Christine Masson et al.

Correspondence to: Christine Masson (christine.masson@umontpellier.fr)

The copyright of individual parts of the supplement might differ from the CC BY 4.0 License. 


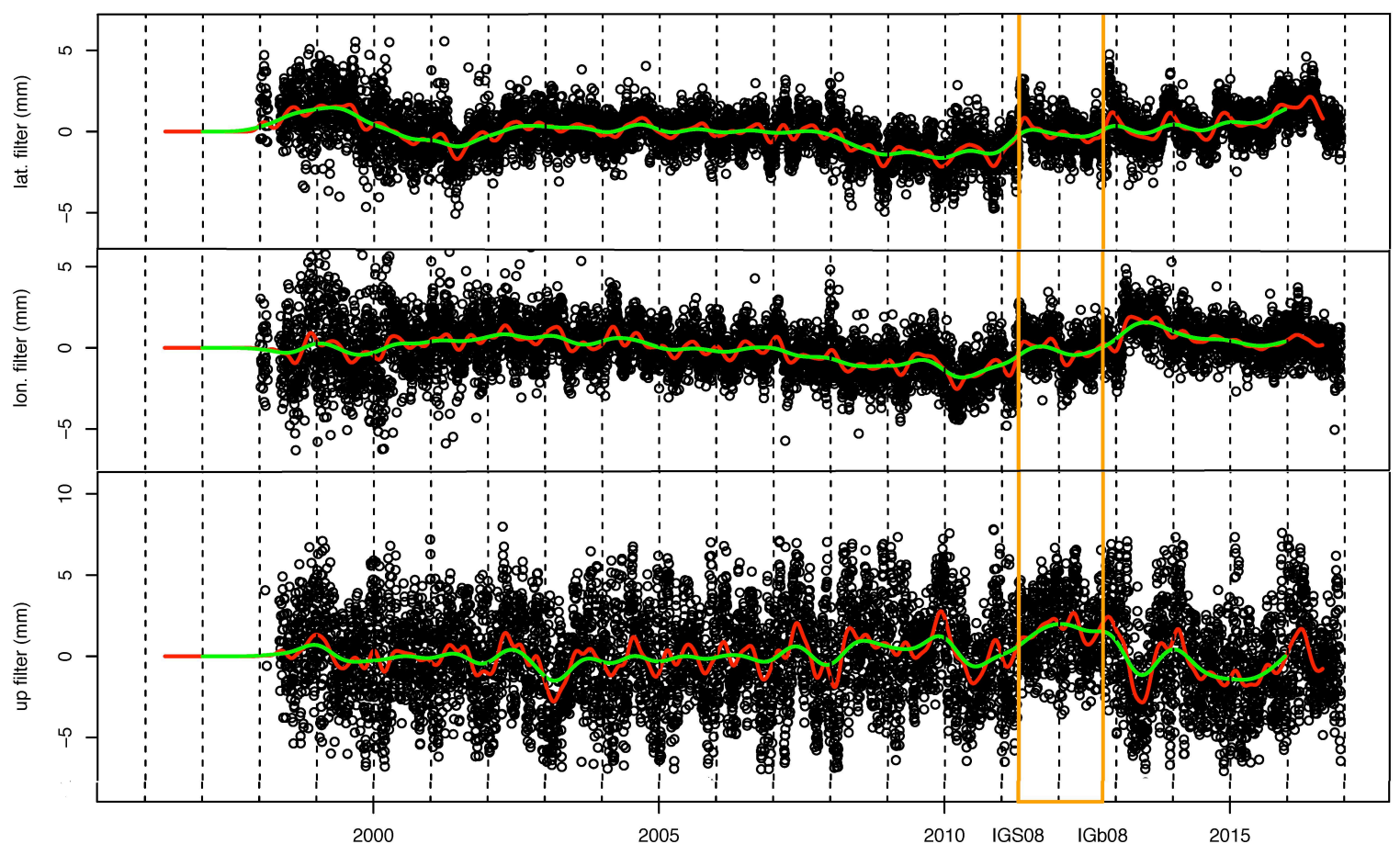

Figure S1 : Common mode stacked filter. Black points are the daily positions, red and green are the 1-month and 1-year time averages. Yellow lines are the IGS05 - IGS08 and IGS08 - IGb08 transitions. 


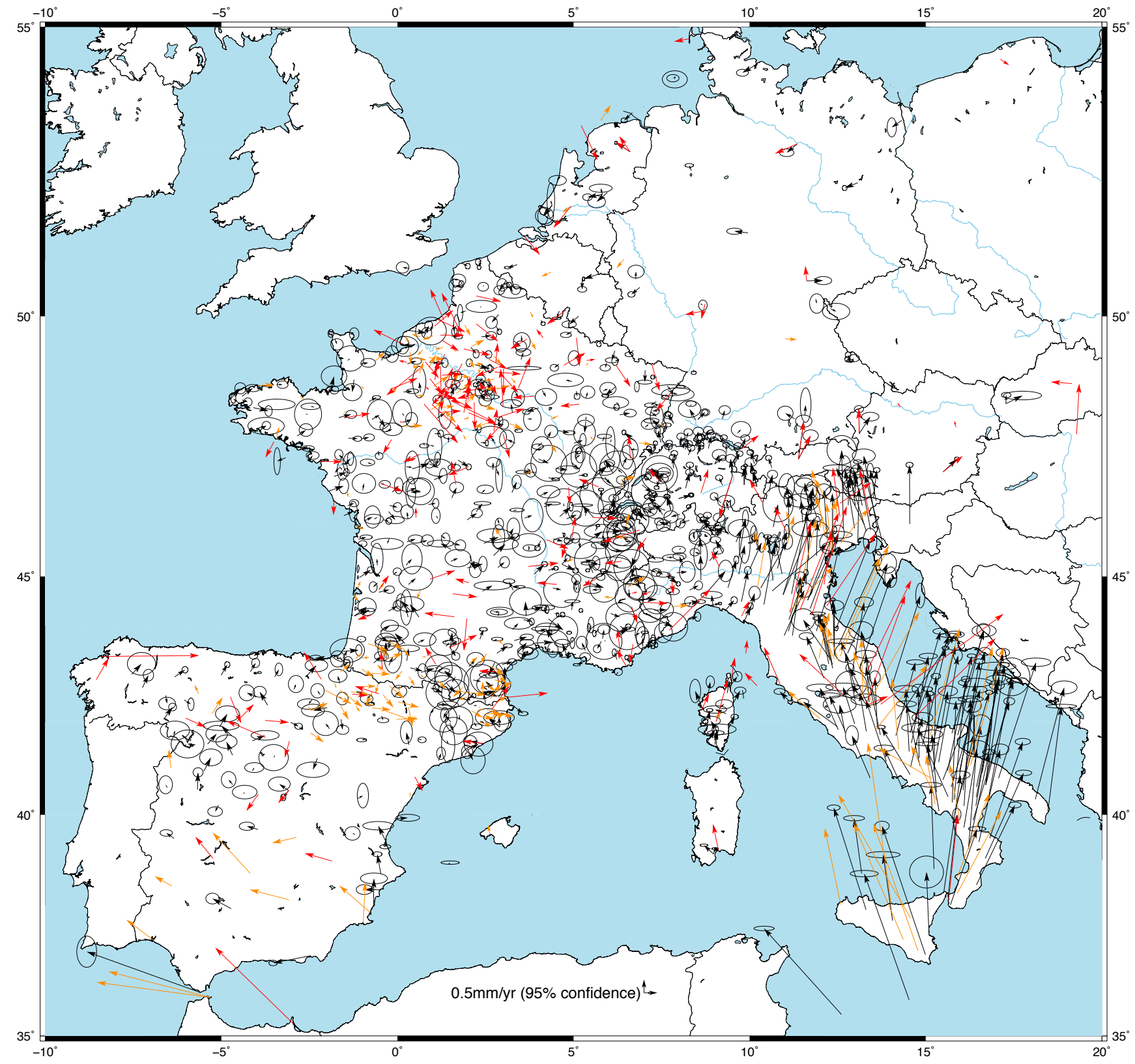

Figure S2 : Horizontal velocities for permanent and campaign stations in France-centered reference frame. In black, the horizontal velocities associated with their $95 \%$ uncertainties, in orange the horizontal velocities whose uncertainty is larger than $0.3 \mathrm{~mm} / \mathrm{yr}$ for which the uncertainties are not represented for graphic reasons, in red, the horizontal velocities of the stations identified as outliers. 

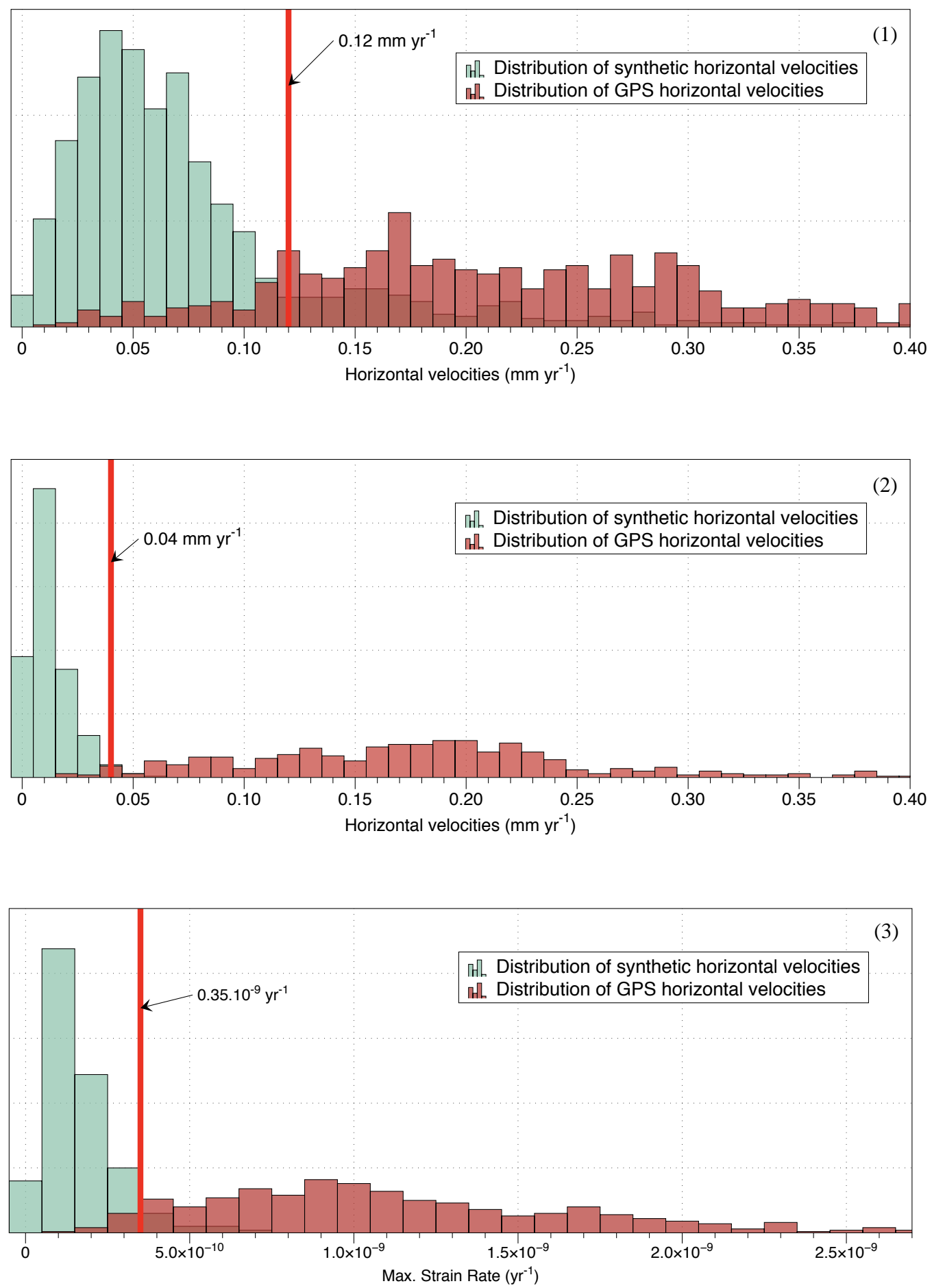

Figure S3 : Histograms of distribution of synthetic data vs. actual data for (1) clustered velocities, (2) smoothed velocities and (3) max strain rate. 


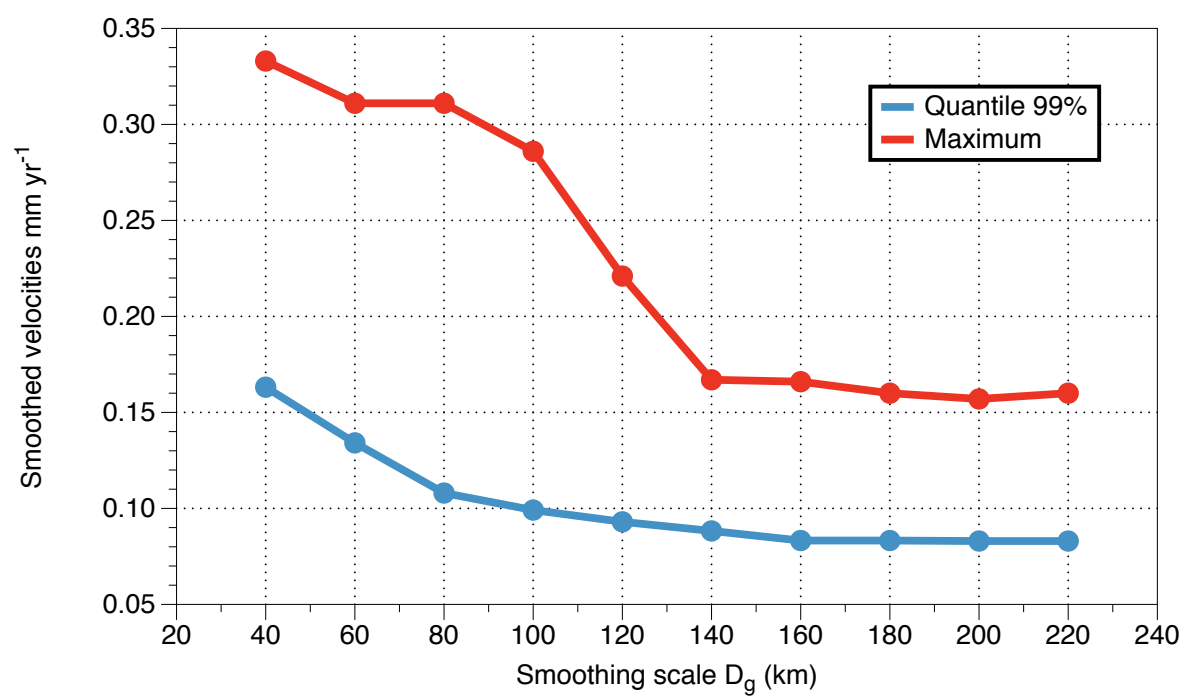

Figure S4 : Evolution of the smoothed velocities (maximum and quantile 99\%) according to the smoothing distance. 


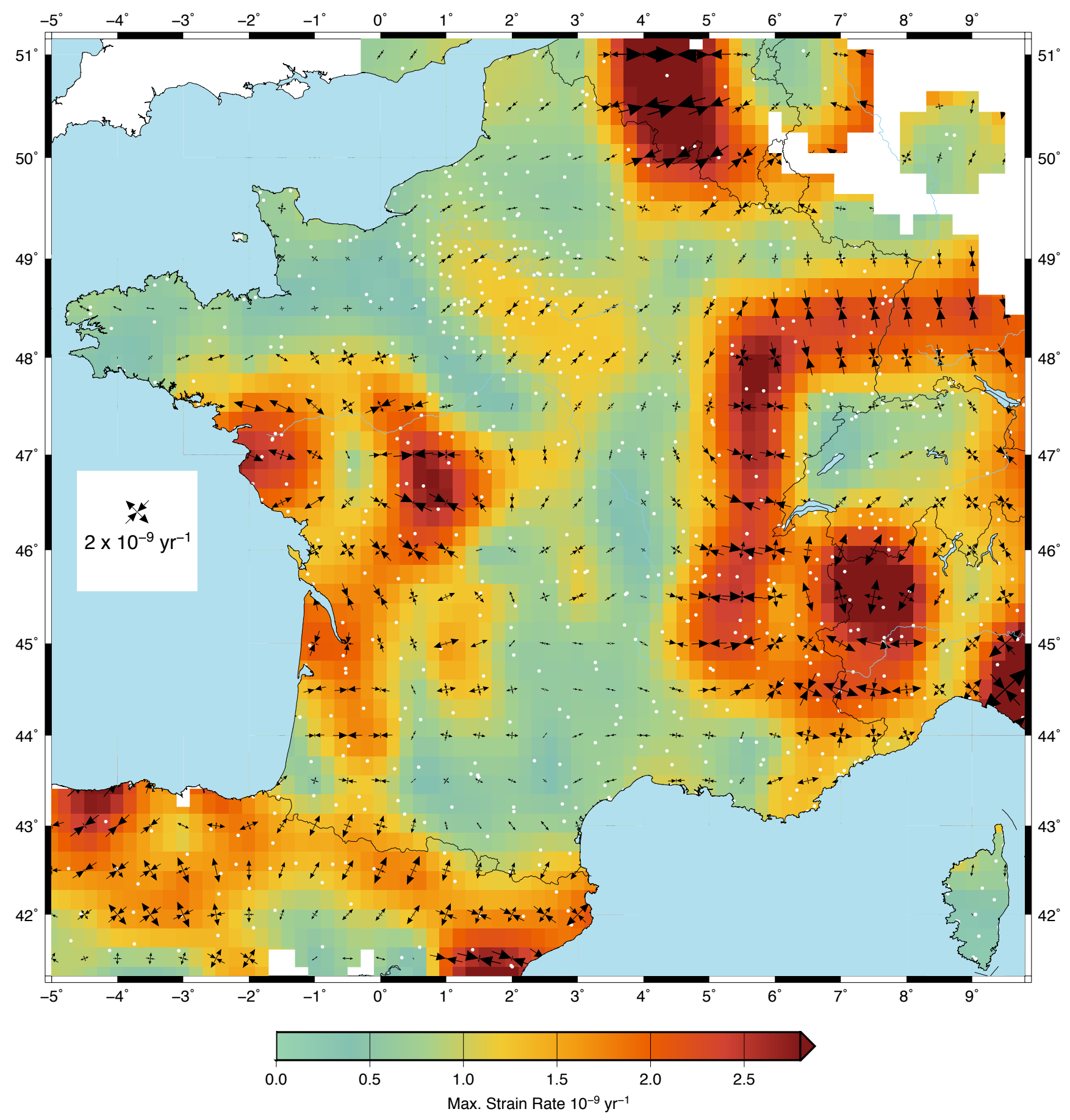

Figure S5 : Smoothed horizontal strain rate field with a grid of 0.1 degrees (strain rate tensors are plotted every 0.5 degrees) without excluding outliers. 


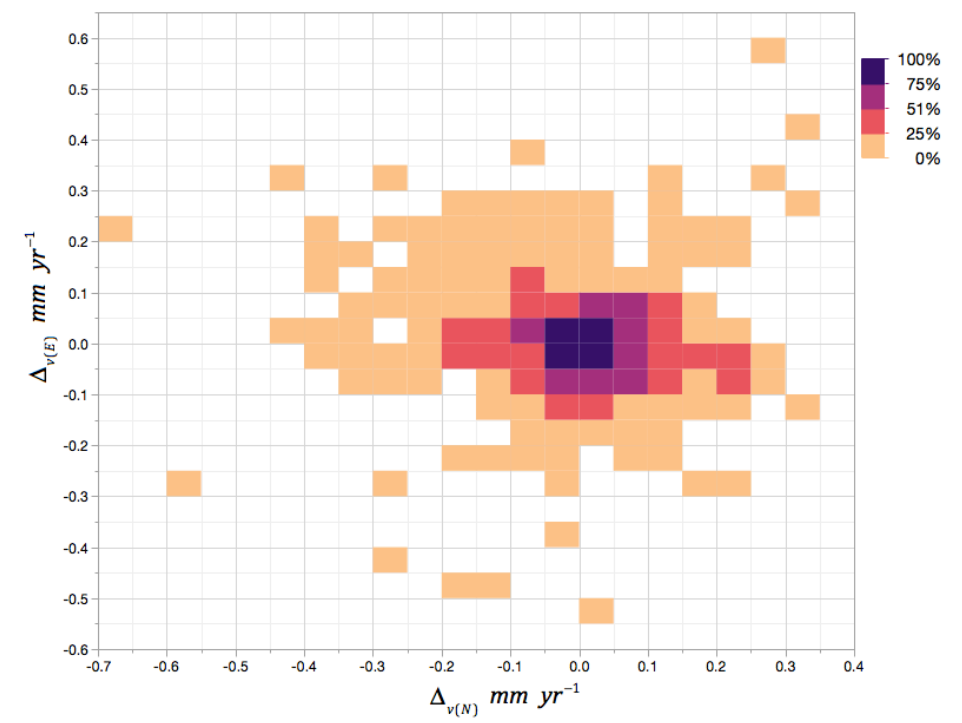

Figure S6 : Diagram of dispersion of differential horizontal velocities between clustered and smoothed velocities, each color represents $25 \%$ of the totality of the data. 

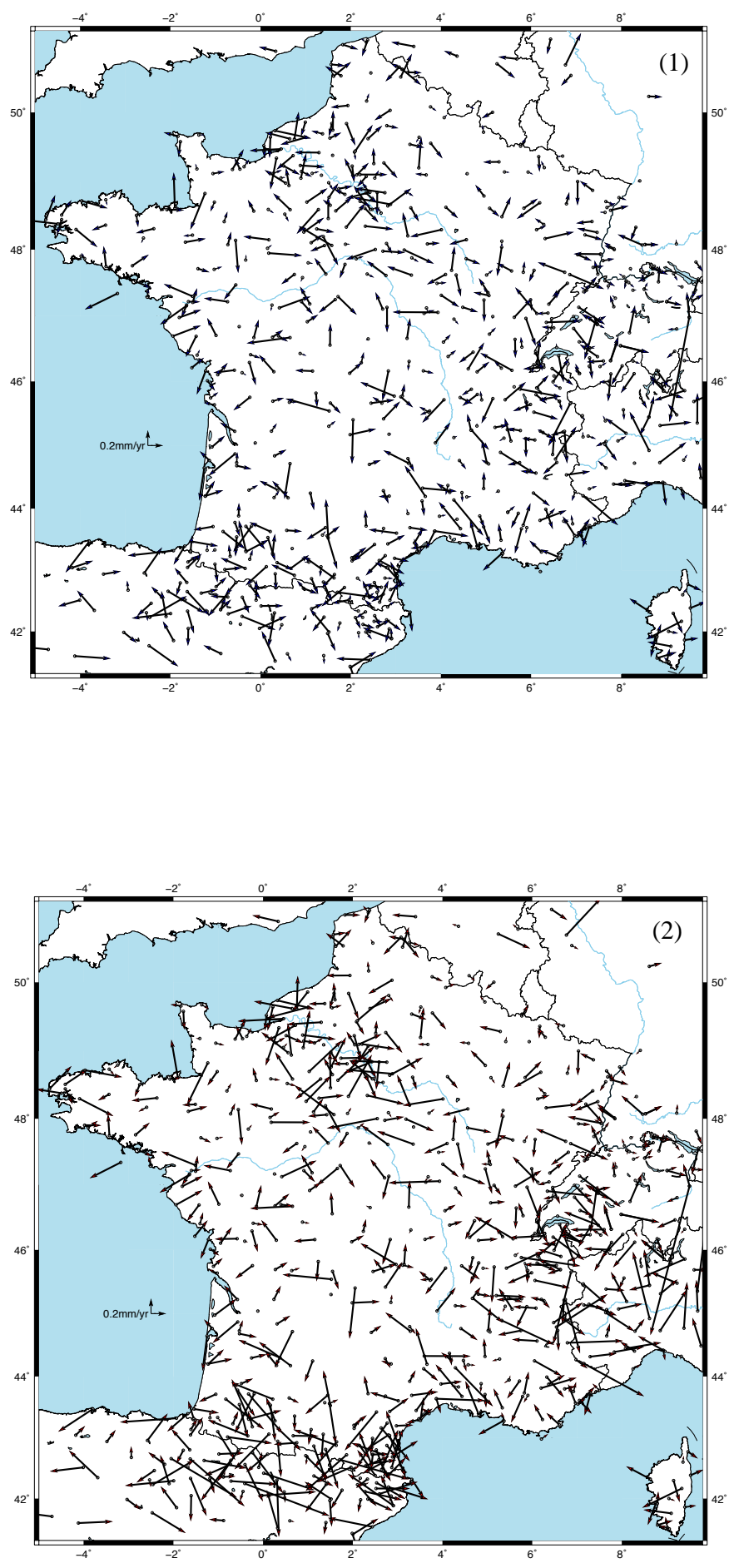


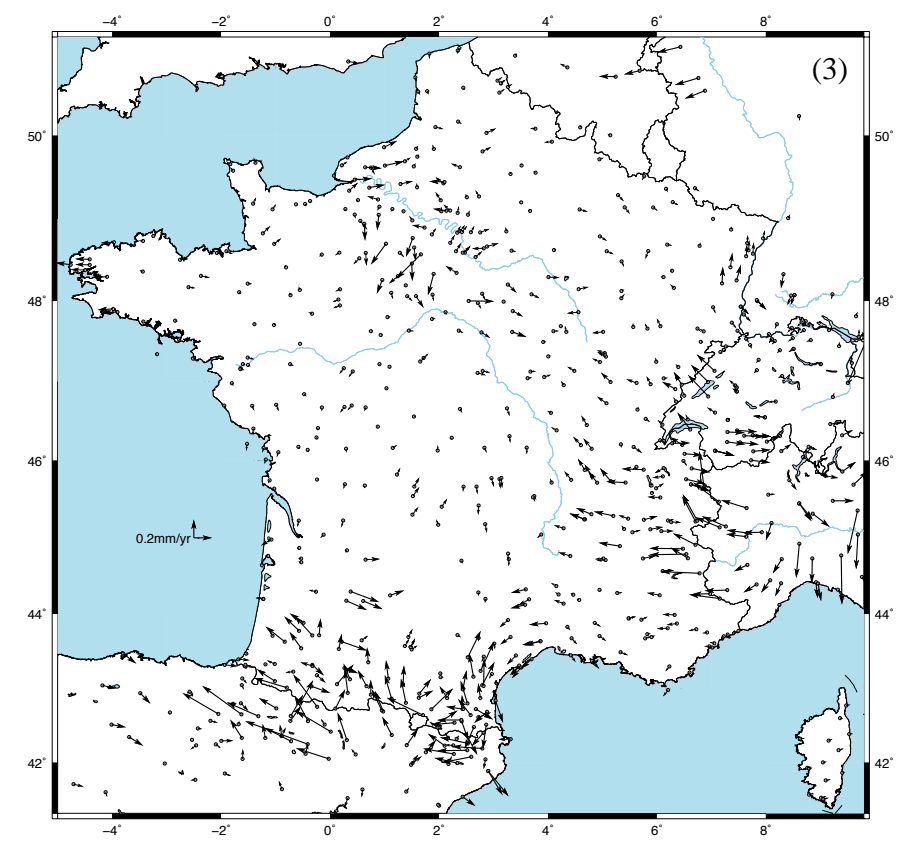

Figure S7 : Differences between (1) the GPS velocities and the clustered velocities, (2) between the GPS velocities and the smoothing velocities and (3) between the velocities obtained from the clustering and from the Gaussian smoothing methods. 